\title{
Impact of Layered Heterogeneity on Transient Saltwater Upconing in Coastal Aquifers
}

Antoifi Abdoulhalik ${ }^{1,2 *}$, Abdelrahman M. Abdelgawad ${ }^{3}$, and Ashraf A. Ahmed ${ }^{2}$

$4 \quad{ }^{1}$ Civil Engineering Department, College of Engineering, Taibah University, Madinah, Saudi Arabia

${ }^{2}$ Department of Civil \& Environmental Engineering, Brunel University London, Kingston Lane, Uxbridge UB83PH, UK

${ }^{3}$ Civil Eng. Department, Faculty of Engineering, Assiut University, Assiut, Egypt

*Corresponding author: Email: antoifi.abdoulhalik@gmail.com Tel. +33686468465

\section{Abstract}

This research investigated the effect of layered heterogeneity on transient saltwater upconing in a laboratory-scale coastal aquifer. The experiments were conducted in a 2Dlaboratory flow tank, and the response of the saltwater wedge to pumping was analysed in a heterogeneous aquifer system, where a low permeability layer was constructed in the middle of the aquifer. The SEAWAT code was used for validation and to perform additional simulations to explore the sensitivity of the critical pumping rate and the critical time to the main parameters characterising the low-permeability layer, which included its permeability, thickness and position. The experimental results showed that the presence of layered heterogeneity noticeably altered the shape and the intrusion length of the upconing wedge without inducing a change in the abstraction rate "triggering" saltwater upconing mechanism compared to the homogeneous case. The numerical results of the layered aquifer provided excellent agreement with the experimental data for both the transient toe length and the shape of the steady-state saltwater wedges. The sensitivity analysis revealed that the critical pumping rate and the critical time was found to decrease considerably with decreasing hydraulic conductivity and thickness of the middle layer, which evidences the higher vulnerability of such layered aquifer systems to the saltwater upconing, in comparison to idealised homogeneous systems. The results nonetheless showed that varying the position of the 
interlayer induced very little change on the critical pumping rate, but the critical time would tend to decrease as the low permeability layer was moved deeper away from the pumping well, particularly for smaller middle layer thickness.

31 Keywords: Seawater Intrusion; Saltwater Upconing; Aquifer salinisation; Laboratory experiments; Numerical modelling; SEAWAT

\section{Introduction}

The landward penetration of seawater in coastal aquifers, known as Seawater Intrusion (SWI), occurs mostly as a result of the over-exploitation the fresh groundwater. Also, factors related to climate change, which include the reduction in freshwater recharge (resulting from drought) and sea level rises, also severely enhance the intrusion mechanism, which subsequently leads to faster contamination. SWI can induce a substantial reduction of the fresh groundwater storage within the aquifer and ultimately lead to the salinization of pumping wells located nearby the coastline. The salinisation of the pumping wells occurs only by the mixing of $1 \%$ seawater (Abdoulhalik \& Ahmed, 2018) and occurs as the freshwater-saltwater transition zone rise towards the bores of the wells, a mechanism called saltwater upconing (Reilly \& Goodman, 1987).

The presence of inherent subsurface heterogeneity within the geological formation is an important factor affecting the saltwater intrusion mechanism. The presence of variations in the permeability within the subsurface not only causes the flow to be disrupted over various length scales, but also has a major contribution in density-dependent flow systems (Simmons et al., 2001; Houben \& Post, 2017). The layered heterogeneous structures are amongst the most encountered forms of subsurface heterogeneity in real life aquifer systems. Many previous SWI studies have used such representations to simulate subsurface heterogeneous conditions (Ketabchi et al., 2014; Liu et al., 2014; Dose et al., 2014; Mehdizadeh et al., 2014; Mehdizadeh 
et al., 2017; Strack et al., 2015). Numerous experimental investigations have shown that layered heterogeneity considerably affects the position of the toe of the intruding wedge (Abdoulhalik \& Ahmed, 2017a; Strack \& Ausk, 2015) as well as the freshwater-saltwater transition-zone dynamics (Lu et al., 2013). Abdoulhalik and Ahmed (2017a) presented experimental evidence of the dependency of the rate of saltwater wedge motion (advancing and receding) as well as the widening of the transition-zone on the stratification pattern of the aquifer. While there is still a substantial need for further analyses of transient SWI in heterogeneous systems (Michael et al., 2017), studies investigating the sensitivity saltwater upconing mechanism to subsurface heterogeneity effects remain even scarcer.

The issue of saltwater upconing mechanism in coastal aquifer has recently been the topic of numerous investigations where idealised homogeneous condition was therein assumed (Johannsen et al., 2002; Mehdizadeh et al., 2015; Noorabadi et al., 2017; Stoeckl \& Houben, 2012; Werner et al., 2009; Wirojanagud \& Charbeneau, 1985; Zhou et al., 2005). Werner et al. (2009) evaluated the saltwater wedge response to various pumping regime and for saltwater densities. Stoeckl and Houben (2012) demonstrated that saltwater upconing mechanism was more sensitive to vertical pumping wells than horizontal pumping wells. Abdoulhalik and Ahmed (2018) examined the effect of hydraulic conductivity on the saltwater upconing mechanism. Their results evidenced that the upconing process was faster in low permeability aquifers. The higher vulnerability of low permeability aquifers to saltwater upconing was further demonstrated in Abdelgawad et al. (2018). They investigated the influence of the pumping well design parameters (depth and location), the saltwater density and aquifer hydraulic conductivity and dispersivity on the critical pumping rate (abstraction rate prompting saltwater upconing mechanism) and the critical time (time taken for the saltwater to reach the well). Their results showed that the critical pumping rate was more sensitive to the variations in the well location than the pumping well depth. They also demonstrated that the critical 
77 pumping rate decreased with increasing saltwater densities while remaining relatively insensitive to dispersivity changes. While all these studies assumed homogenous conditions, an assessment of the impact of typical aquifer stratification on saltwater upconing mechanism and the associated transient related phenomena occurring within the rising freshwater-saltwater transition zone has never been provided.

82 Therefore, the aim of this study was to provide an insight into the effect of layered

83 heterogeneity on the saltwater upconing mechanism, using laboratory and numerical modelling 84 experiments. This study is a very first attempt to provide an insight on transience SWI under pumping conditions while incorporating in typical heterogeneous effects in laboratory-scale aquifer model. Several experiments were conducted on a layered aquifer where a low

87 permeability $(\mathrm{K})$ layer was set in the middle part of the aquifer. The objectives of this study were twofold: 1) to examine quantitatively and qualitatively the impact of layered 89 heterogeneity on the temporal evolution of the shape and location of the upconing saltwater 90 wedge in a laboratory-scale coastal aquifer system; 2) to explore the sensitivity of the critical 91 pumping rate to the main parameters characterizing the heterogeneity effects, which included 92 herein the middle layer permeability, its thickness and position into the aquifer. The laboratory 93 experiments were conducted in a 2D flow tank where automated image analysis was 94 implemented, and the SEAWAT code was used for numerical modelling. 


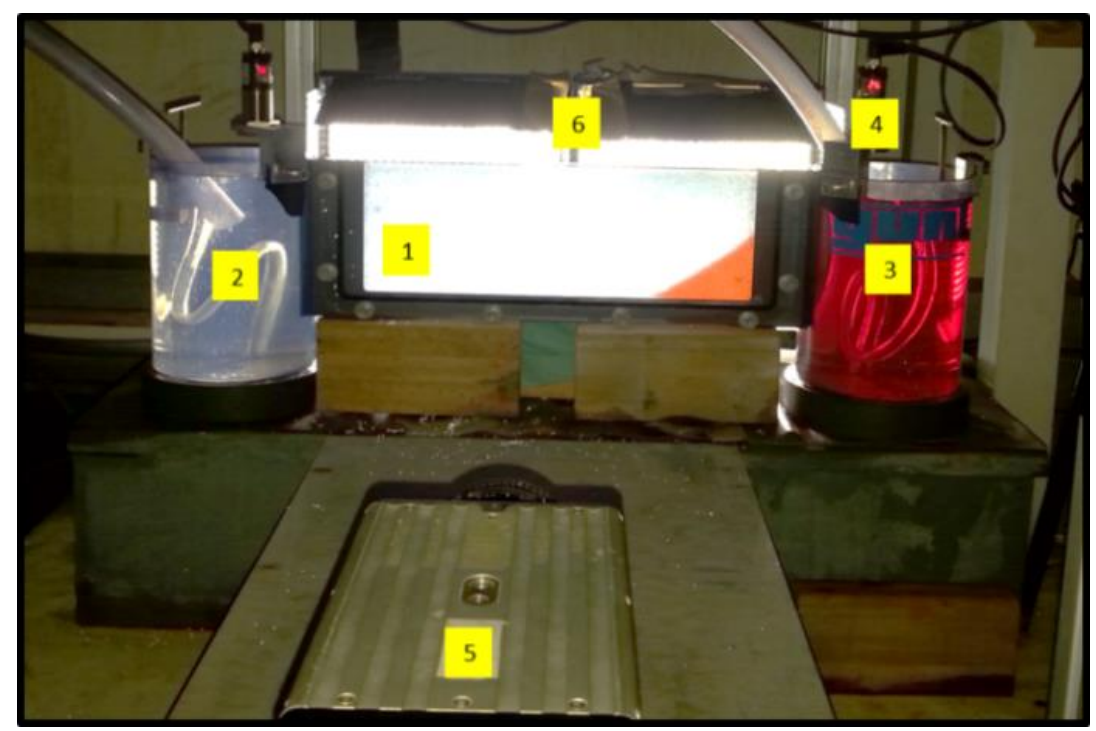

Figure 1 Photograph of the experimental setup; 1) porous media chamber; 2) freshwater reservoir; 3) saltwater reservoir; 4) ultrasonic sensors; 5) high-speed camera; 6) LED 100 lights

The cross section of an unconfined coastal aquifer was simulated using a laboratory flow tank of dimension $0.38 \mathrm{~m} \times 0.15 \mathrm{~m} \times 0.01 \mathrm{~m}$ (Figure 1 ). The flow tank was composed by three distinct compartments: a central chamber and two circular side reservoirs. The porous media was simulated by filling the central chamber with clear glass beads from Whitehouse Scientific $®$. At the boundary between the central chamber and the side reservoirs were located

107 fine mesh acrylic screens. The aperture diameter of these meshes was around $0.5 \mathrm{~mm}$, which was sufficiently small to maintain the glass beads within the central chamber and large enough to enable the water to flow through.

110 Two different bead sizes were used in the experiments, namely $780 \mu \mathrm{m}$ and $1090 \mu \mathrm{m}$. The

111 hydraulic conductivity $(\mathrm{K})$ of each was estimated using in situ measurement within the

112 experimental flow tank using Darcy's law, and the average hydraulic conductivity K were

113 estimated at $85 \mathrm{~cm} / \mathrm{min}$ and $36 \mathrm{~cm} / \mathrm{min}$, for the beads $1090 \mu \mathrm{m}$ and $780 \mu \mathrm{m}$, respectively. 
114 The heterogeneous case was simulated by forming a low K layer in the middle part of the

115 aquifer using the beads of $\mathrm{K}=36 \mathrm{~cm} / \mathrm{min}$. The thickness of the low $\mathrm{K}$ layer accounted for no

116 more than one-third of the total saturated thickness of the aquifer that equalled $\mathrm{h}=136 \mathrm{~mm}$.

117 The left and right side reservoirs were used to simulate constant freshwater-head and saltwater-

118 head boundary conditions, respectively. The left side reservoir was filled with cold tap water,

119 and the right side reservoir was filled with saltwater with a density of $1020 \mathrm{~kg} / \mathrm{m}^{3}$. The latter was dyed using red food colour to distinguish it from the freshwater.

121 The pumping well was simulated by inserting a needle vertically into the porous media which acted as a point sink. The needle was $50 \mathrm{~mm}$ long and was connected to a peristaltic pump (Watson Marlow $101 \mathrm{U} / \mathrm{R}$ ) using a flexible hose. The internal diameter of the hose was $4.8 \mathrm{~mm}$ and was adjusted such that tip of the needle was located at $85 \mathrm{~mm}$ from the aquifer bottom (i.e. the bottom of the tank) and $190 \mathrm{~mm}$ away from the coastline (i.e. the boundary of the saltwater reservoir). Similar methods were used in Abdoulhalik \& Ahmed (2018).

The saltwater intrusion experiment was initiated upon lowering the overflow outlet of the freshwater reservoir such that to impose an initial constant freshwater head of $135.7 \mathrm{~mm}$ while maintaining a constant saltwater head of $129.7 \mathrm{~mm}$. This initial head boundary difference of $130 \mathrm{dh}=6 \mathrm{~mm}(\mathrm{dh}=135.7-129.7=6 \mathrm{~mm})$, corresponded to a hydraulic gradient of 0.0158 . This gradient is a typical value used in similar laboratory studies (Abdelgawad et al., 2018; Abdoulhalik \& Ahmed, 2018) and within the range of values measured in some real coastal aquifers (Ferguson \& Gleeson, 2012). This initial hydraulic gradient allowed the dense saline water to penetrate the porous media until the system reached steady state condition.

135 Once the initial steady state was established, the abstraction was initiated by switching on the 136 pump. The pumping rate was first set to an initial rate of $0.09 \mathrm{~mL} / \mathrm{s}$ and was after that gradually incremented by $0.1 \mathrm{~mL} / \mathrm{s}$. After each increment of the pumping rate, the system was allowed 
to reach a steady state condition. Once the saltwater upconing mechanism was observed, the

139 critical pumping rate was recorded, and the pump was turned off. The same procedure was

140 adopted in Abdoulhalik \& Ahmed (2018). The images recorded throughout the experiments

141 were after that post-processed such that the saltwater intrusion length could be calculated and

142 the experimental images showing salt concentration distribution within the aquifer could be 143 provided.

\section{$144 \quad 2.3$ Numerical model and procedure}

The MODFLOW variable-density flow code SEAWAT (Guo \& Langevin, 2002) was

146 selected for the numerical simulations. The porous media was represented by a rectangular 147 model of dimensions $38 \times 13 \mathrm{~cm}$ discredited uniformly using a size mesh of $0.2 \mathrm{~cm}$. The

148 longitudinal dispersivity was set at $0.1 \mathrm{~cm}$, and the transverse dispersivity was considered to

149 be $1 / 10$ of the longitudinal dispersivity. The dispersivity values and the element dimensions

150 satisfied the Peclet number criterion (Voss \& Souza, 1987). Freshwater and saltwater (c = 28.96

$151 \mathrm{~g} / \mathrm{l}$ ) hydrostatic boundary conditions were applied to the left and right sides of the porous media domain, respectively. The simulation time step was set to $0.5 \mathrm{~min}$.

The initial condition of the model corresponded to an aquifer fully saturated with freshwater.

154 The saline water penetrated the aquifer in the first stress period, as the freshwater and saltwater

155 head boundaries were set at $13.57 \mathrm{~cm}$ and $12.97 \mathrm{~cm}$, respectively. The pumping well was

156 simulated at the design location, and the abstraction was initiated in the second stress period,

157 with an initial discharge rate of $5.4 \mathrm{~cm}^{3} / \mathrm{min}$ (i.e. $0.09 \mathrm{~mL} / \mathrm{s}$ ). The stress period was set to 50

158 min to allow the system to reach steady state. The discharge rate of the well was after that

159 gradually incremented by $6 \mathrm{~cm}^{3} / \mathrm{min}$ (i.e. $0.1 \mathrm{~mL} / \mathrm{s}$ ) until the saltwater upconing process was

160 reproduced. The pumping rate was finally reset to zero. A summary of the parameters involved

161 in the numerical simulations is shown in table 1. 
Table 1 Summary of the numerical parameters

163

164

165

166

167

168

169

\begin{tabular}{c}
\hline Input Parameters \\
\hline Domain length $(\mathrm{cm})$
\end{tabular}

Domain height $(\mathrm{cm})$

13

Element size $(\mathrm{cm})$

0.2

Hydraulic Conductivity $(\mathrm{cm} / \mathrm{min})$

85

Porosity

0.3

Longitudinal dispersivity $(\mathrm{cm}) \quad 0.1$

Transversal dispersivity $(\mathrm{cm}) \quad 0.01$

Freshwater density $\left(\mathrm{kg} / \mathrm{m}^{3}\right) \quad 1000$

Saltwater density $\left(\mathrm{kg} / \mathrm{m}^{3}\right) \quad 1020$

Freshwater head $(\mathrm{cm}) \quad 13.57$

Saltwater head $(\mathrm{cm}) \quad 12.97$

Abstraction rates $(\mathrm{mL} / \mathrm{s}) \quad 0.49$

Stress period (min)

Value

38

(3)

2

1

12.97

170 
Heterogeneous Experiment
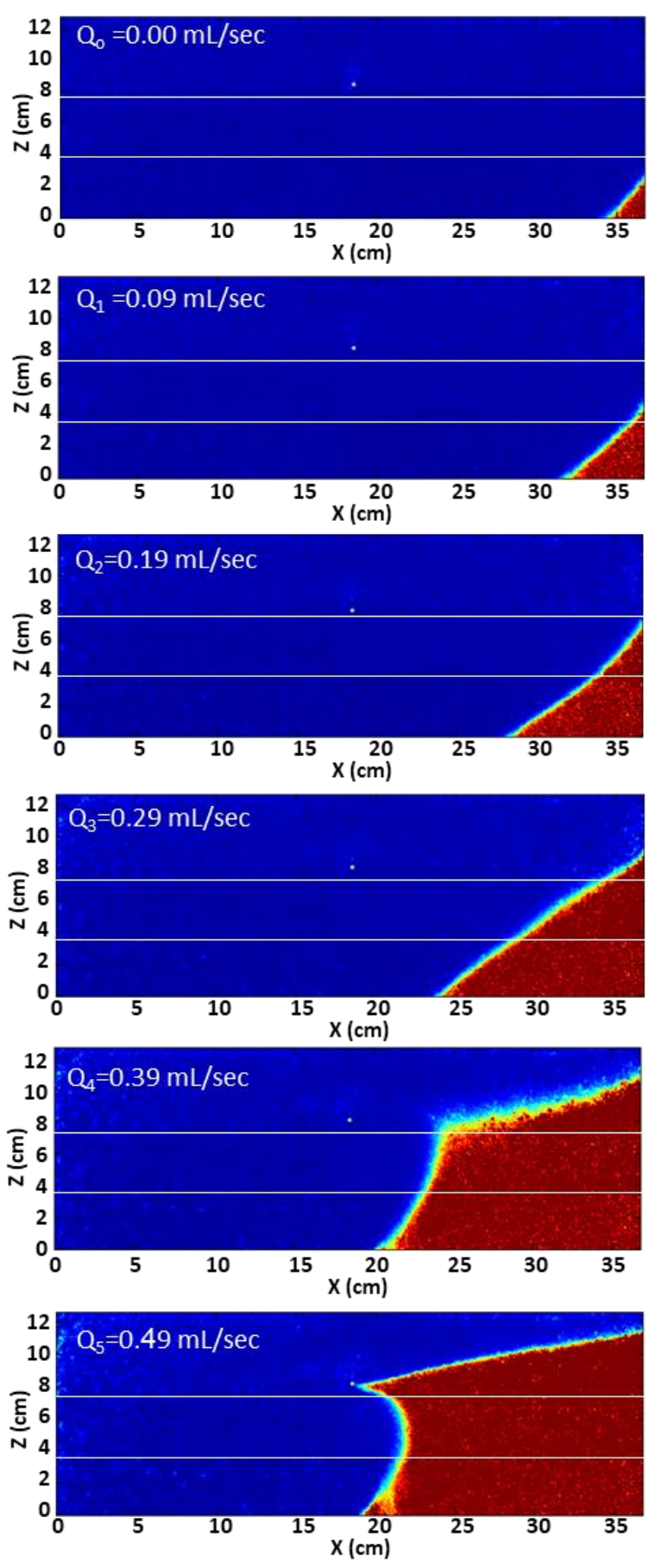

Homogenous Experiment
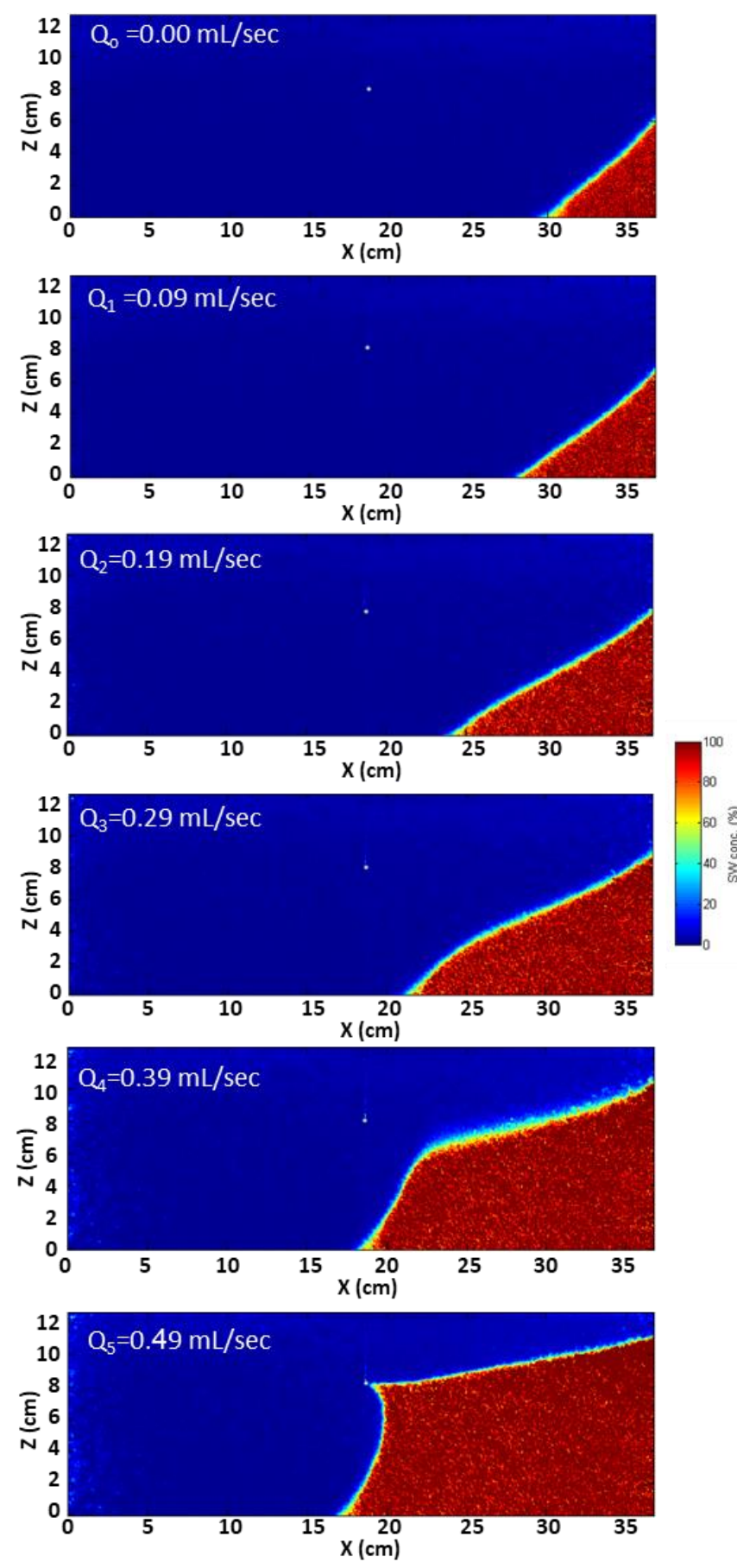

174 Figure 2. Experimental concentration colour maps showing the saltwater upconing

175 process at different pumping rates in the heterogeneous case (left) and homogeneous case

176 of Abdoulhalik and Ahmed (2018) (right) 
177 The analysis of heterogeneity effects on saltwater upconing mechanism required the 178 comparison of the heterogeneous results to data obtained in an identical aquifer but in 179 homogeneous conditions, where the same hydrostatic boundary conditions and the same 180 pumping rates were implemented. Therefore, the homogeneous results reported previously in 181 Abdoulhalik \& Ahmed (2018) were used here for comparison. Note that the hydraulic 182 conductivity of the homogeneous case corresponded to the hydraulic conductivity of the $1090 \mu \mathrm{m}$ beads used in the high $\mathrm{K}$ layers in the heterogeneous setting, as the size of the

184 beads used in both cases was the same.

185 Figure 2 shows the steady-state concentration colour maps of the saltwater wedge at the various 186 pumping rates for the heterogeneous and homogeneous cases. The initial intrusion length was 187 visibly much smaller in the heterogeneous case for all the pumping rates tested. The saltwater 188 intrusion length extended further inland as the abstraction was initiated. The toe length 189 remained noticeably smaller in the heterogeneous case for all the pumping rates tested. The

190 final upconing stage was considered when the freshwater/saltwater interface crossed the bore 191 of the well, and the saltwater wedge reached steady state condition. Laboratory observations revealed that the abstraction rate that caused the occurrence of the saltwater upconing process was $\mathrm{Q}=0.49 \mathrm{~mL} / \mathrm{s}$ in both the heterogeneous and homogeneous cases. Figure 2 nonetheless

194 shows that the intrusion length and the overall shape of the upconing wedge were somewhat 195 altered by the presence of the middle low K layer in the heterogeneous case. The widening of 196 the transition zone was therein noticeably greater, especially as the wedge approached the bore 197 of the well $(\mathrm{Q}=0.39 \mathrm{~mL} / \mathrm{s})$, and at the final upconing stage $(\mathrm{Q}=0.49 \mathrm{~mL} / \mathrm{s})$ whereas it 198 remained relatively thin in the homogeneous case. The final shape of the upconing wedge also 199 exhibited a rather bulged shape in the top layer, while it appeared rather curved in the 200 homogeneous case. 
201 The values of each steady state toe length are given in table 2, and the transient toe length data

202 are shown in Figure 3. The data show that the toe length values were greater as the pumping

203 rate increased. The data also show that for equivalent pumping rate increment, the extent of the

204 toe penetration of the saltwater wedge was smaller in the heterogeneous case compared to the

205 homogeneous case. The difference decreased noticeably as the interface approached the well.

206 The data show that the toe length was $49 \%, 34 \%, 17 \%, 9.4 \%$ and $10.7 \%$ greater in the

207 homogeneous case than in the heterogeneous case, for $\mathrm{Q}=0.09,0.19,0.29,0.39$, and 0.49

$208 \mathrm{~mL} / \mathrm{s}$, respectively. Also, for equivalent pumping rate increment, figure 3 shows little

209 difference in the toe migration rate between the heterogeneous and homogeneous cases, which

210 indicates that the presence of the middle low permeability layer did not have a substantial effect

211 on the sensitivity of the toe movement to modification of the pumping regime. 

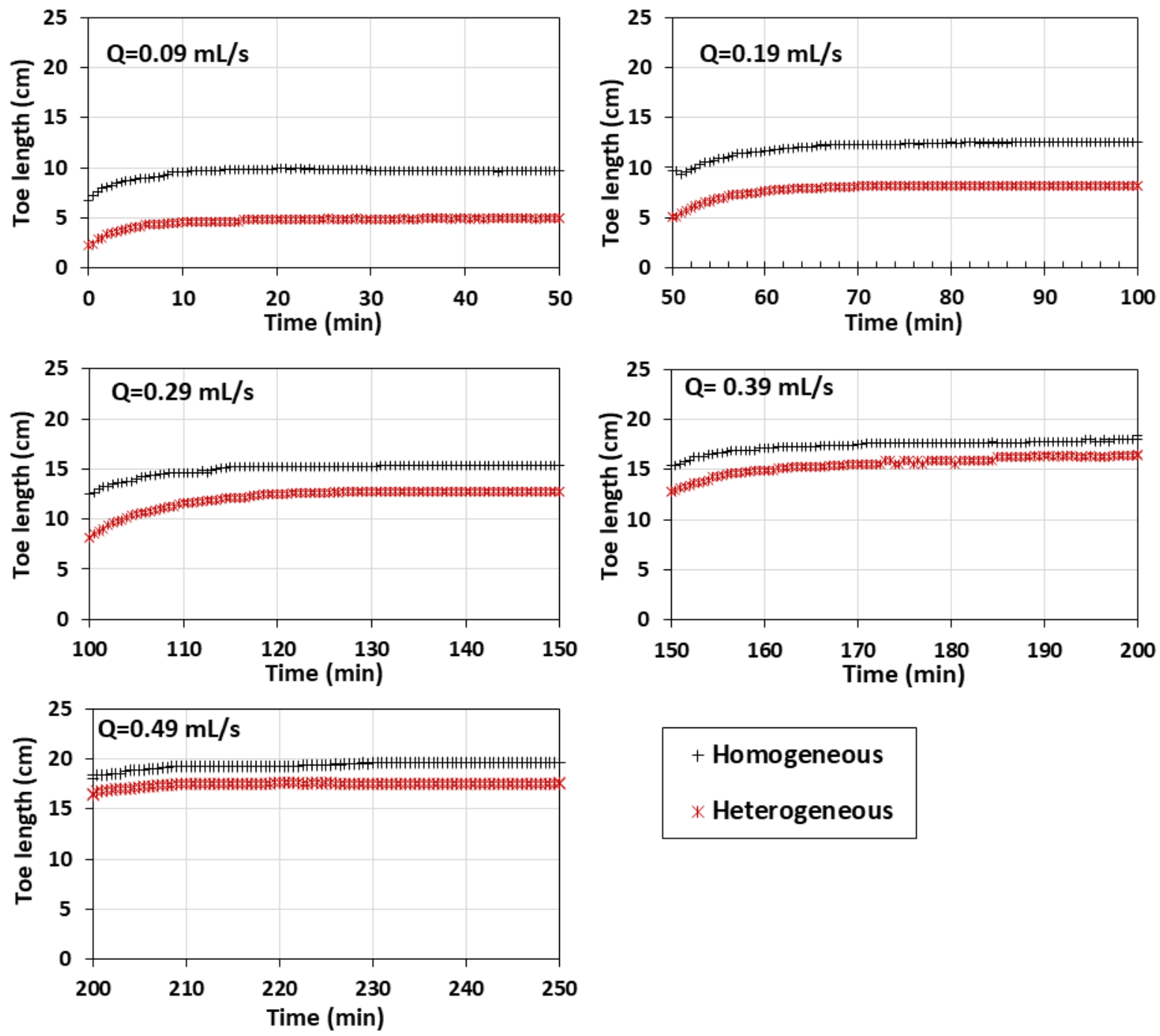

+ Homogeneous

$*$ Heterogeneous

Figure 3. Transient experimental toe length data of the heterogeneous case (red points) and the homogeneous case of Abdoulhalik and Ahmed (2018) (black points)

Table 2 Steady-state toe length data in the heterogeneous case and the homogeneous case

217 of Abdoulhalik and Ahmed (2018)

\begin{tabular}{llccccc}
\hline Pumping rate $(\mathrm{mL} / \mathbf{s})$ & 0.09 & 0.19 & 0.29 & 0.39 & 0.49 \\
\hline \multirow{2}{*}{ Toe length $(\mathbf{c m})$} & Homogeneous & 9.8 & 12.5 & 15.4 & 18.0 & 19.6 \\
\cline { 2 - 7 } & Heterogeneous & 5 & 8.2 & 12.8 & 16.3 & 17.5 \\
\hline
\end{tabular}

220 data are shown in Figure 4. The figure shows that the interruption of the pump caused the

221 seaward motion of the tip of the cone moved rapidly away from the well towards the seaside, 
222 with a substantial distortion of the wedge observed in the heterogeneous case. This delay was

223 probably due to the slower repulsion of the saline water within the low permeability layer. The

224 noticeable widening of the transition zone often associated with seawater retreat was visibly

225 more pronounced in the heterogeneous case. Figure 5 shows that the migration rate of the toe

226 of the saltwater wedge was nearly similar during the retreat, albeit somewhat faster in the

227 heterogeneous case at the start, due to the slightly higher flow velocity at the bottom layer, as

228 observed in previous studies (e.g. Abdoulhalik \& Ahmed, 2017a).

229 
Heterogeneous Experiments
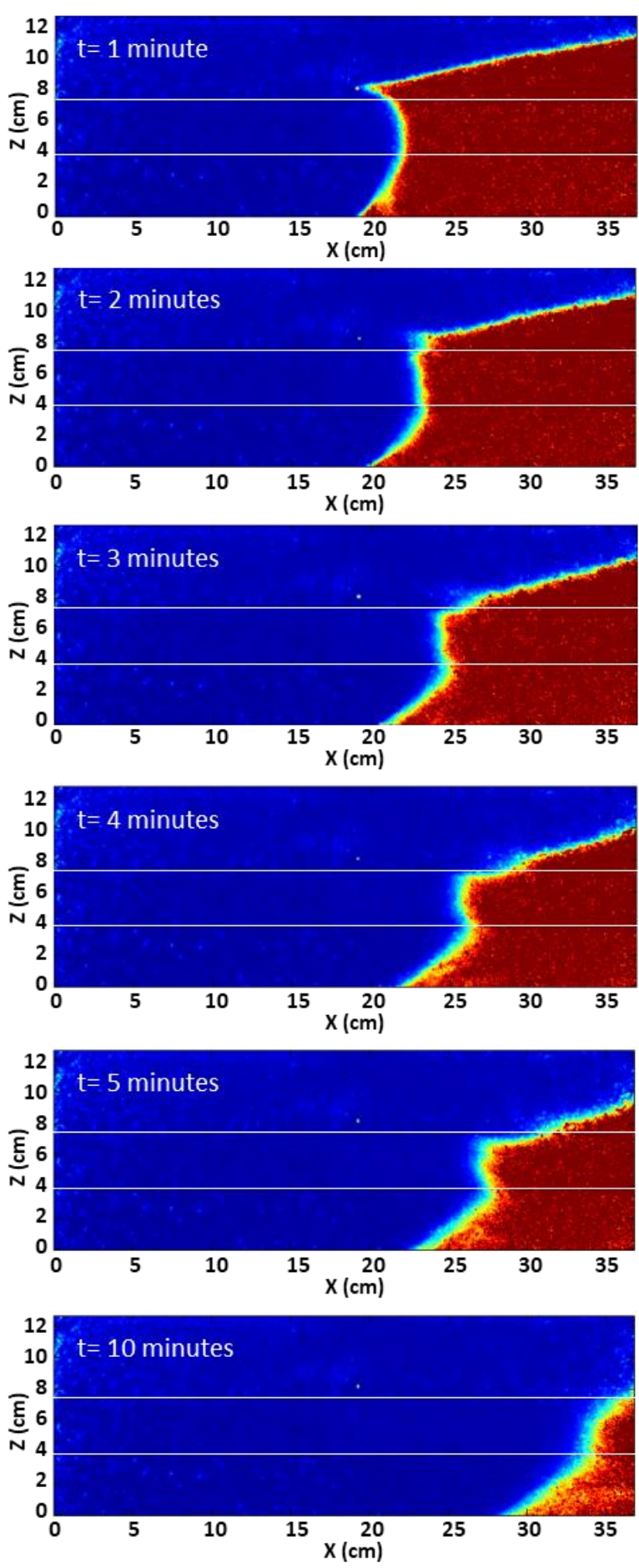

Homogenous Experiments
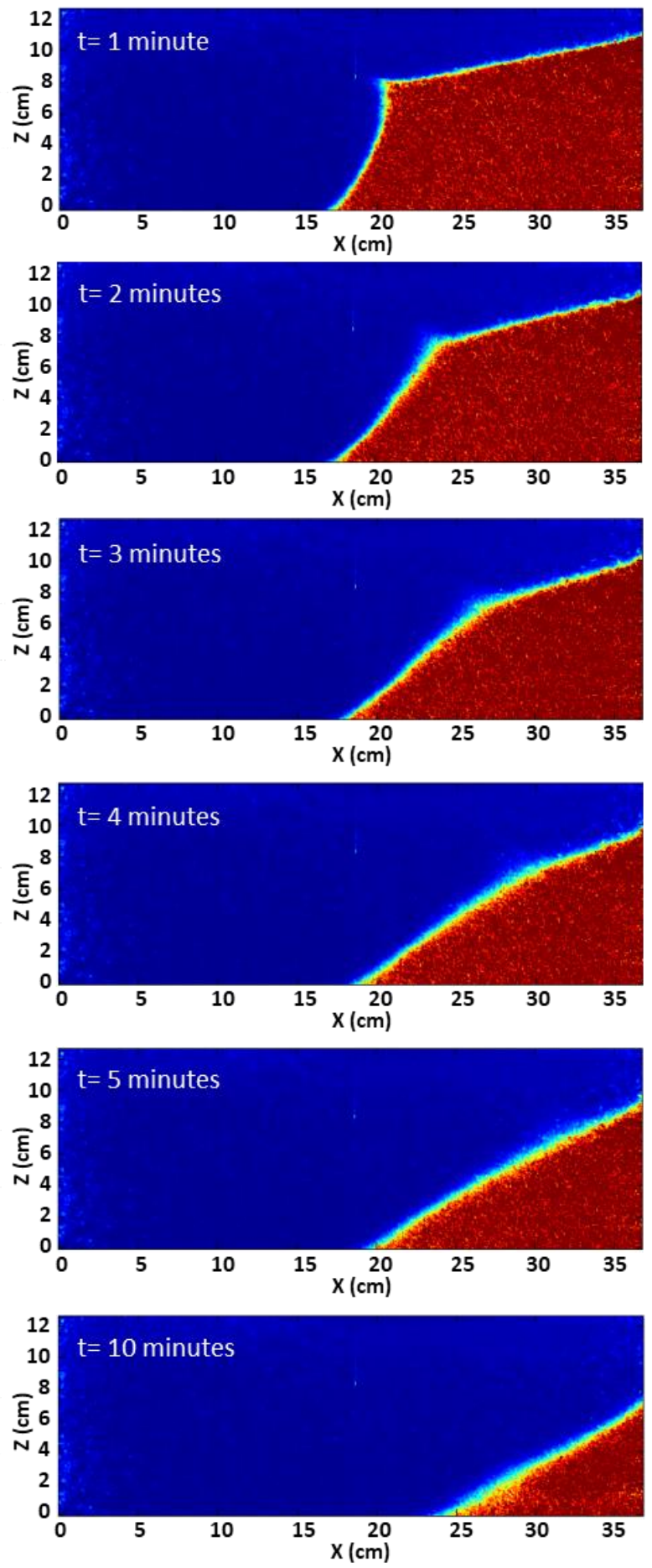

231 Figure 4. Experimental concentration colour maps of the receding process in the 232 heterogenous case (left) and in the homogeneous case of Abdoulhalik and Ahmed (2018) 233 (right) 


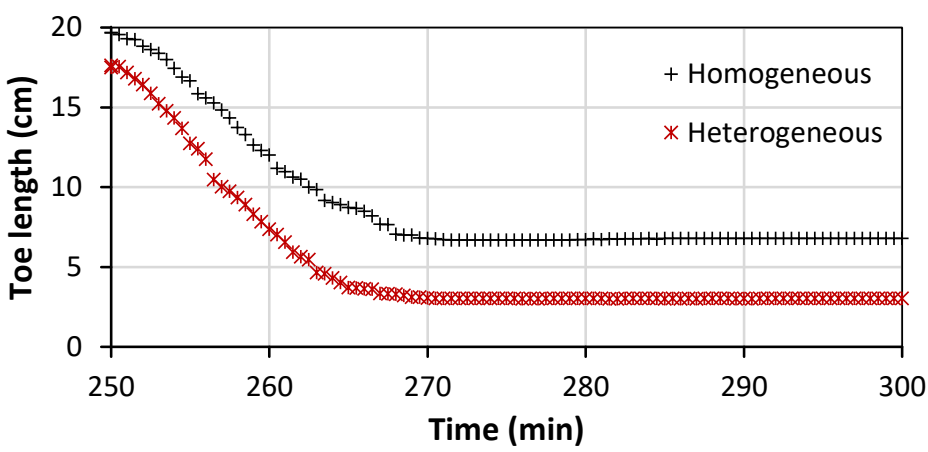

236 Figure 5. Toe length data of the receding wedge in the heterogeneous case (red points)

237 and the homogeneous case of Abdoulhalik and Ahmed(2018) (black points)

\subsection{Numerical modelling}

239 The numerical model SEAWAT was used for the simulation of the experimental data of the

240 heterogeneous scenario. The comparison was both qualitative (by comparing the saltwater

241 wedge shape), and quantitative (by comparing the transient toe length data).
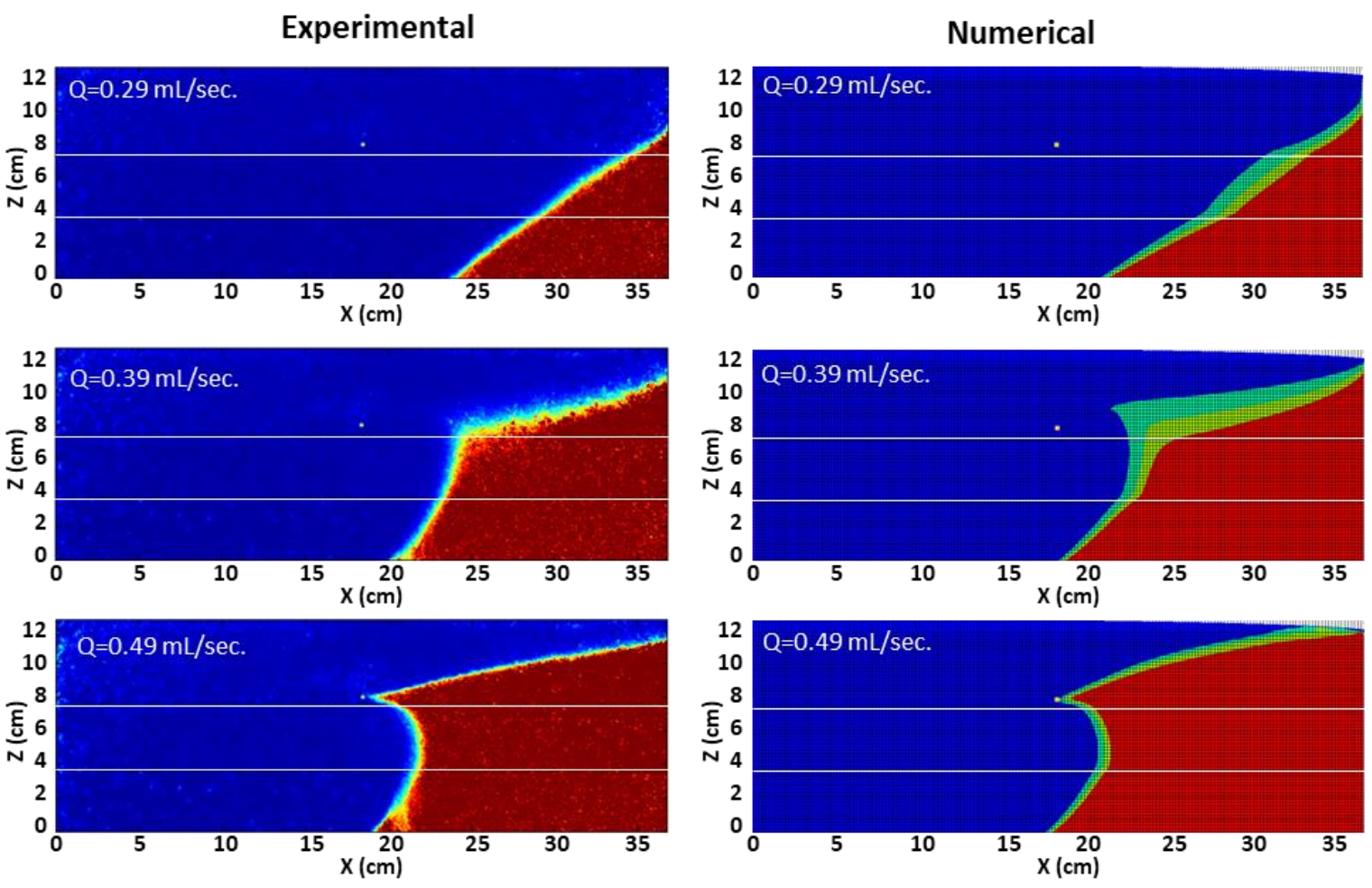

(a)

(b)

243 Figure 6 Comparison between the a) experimental and b) numerical steady-state

244 saltwater wedges for $\mathbf{Q}=\mathbf{0 . 2 9}, \mathbf{0 . 3 9}, \mathbf{0 . 4 9} \mathrm{mL} / \mathrm{s}$ in the heterogeneous case 

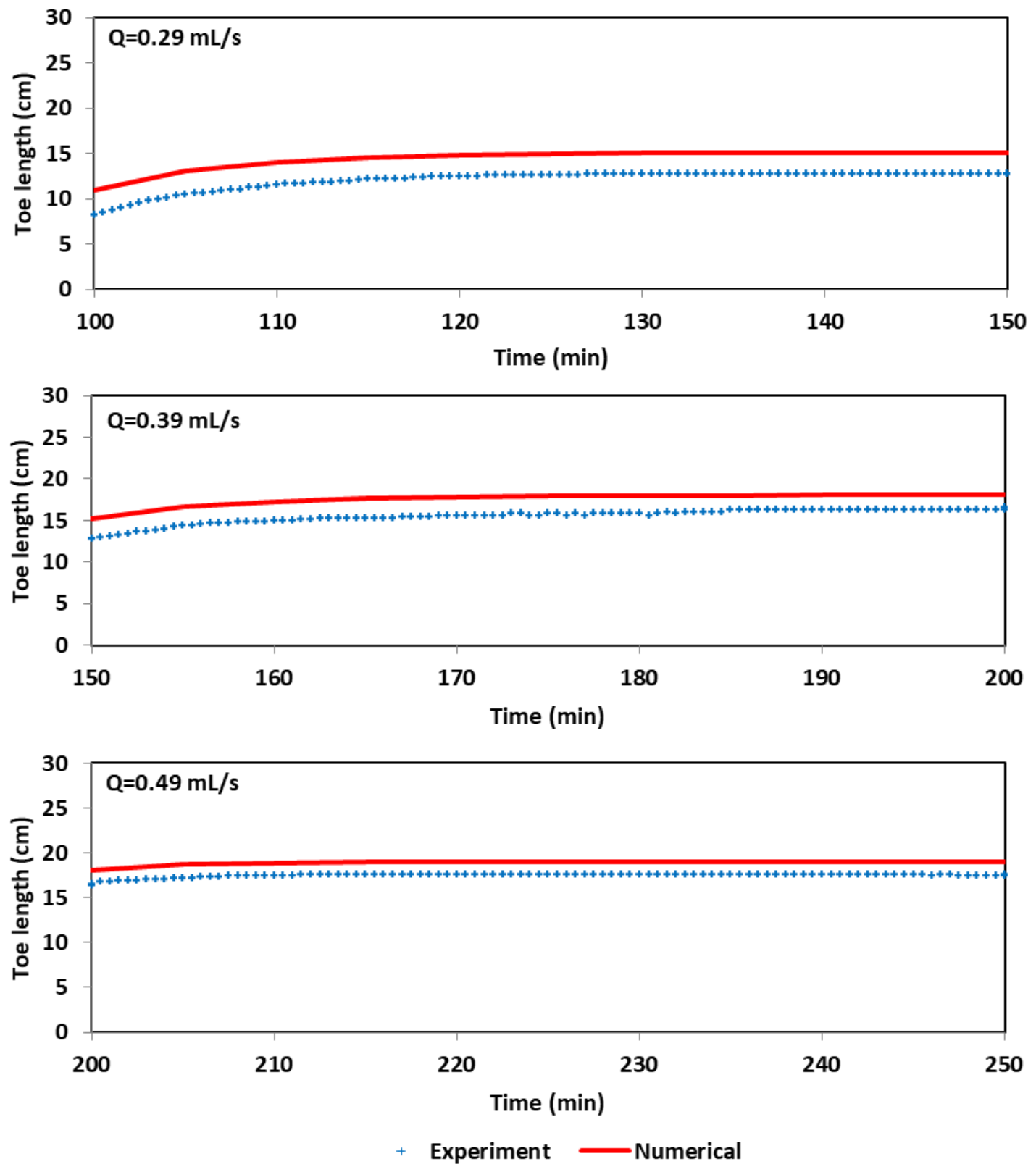

246 Figure 7. Comparison between the transient experimental and numerical model toe 247 length data during abstraction for $Q=0.29,0.39$ and $0.49 \mathrm{~mL} / \mathrm{s}$ in the heterogeneous case

248 Figure 6 compares the steady-state saltwater wedges for different pumping rates in the physical

249 and numerical models. The results show that the numerical model could reproduce relatively

250 well the overall shape of the saltwater wedge, albeit the widening of the transition zone within

251 the low permeability layer was slightly more pronounced than in the physical model, especially

252 before the upconing stage. The numerical model could predict relatively well the evolution 
253 from wide to thin transition zone conditions as the well reached upconing condition, in 254 agreement with the experimental observations. The upconing wedge was relatively well 255 depicted despite some minor visible discrepancies at the seaside boundary.

256 Figure 7 shows that the numerical model produced excellent matching with the physical 257 experiment for the transient toe length data. The transient toe length was in overall slightly 258 over-predicted in the numerical model. The percentage difference between experimental and 259 numerical results was nonetheless fairly reasonable for each pumping rate, averaging 260 maximum values of about $15 \%, 13 \%$ and $8 \%$ for $\mathrm{Q}=0.29 \mathrm{~mL} / \mathrm{s}, 0.39 \mathrm{~mL} / \mathrm{s}$ and $0.49 \mathrm{~mL} / \mathrm{s}$, 261 respectively. The comparison of the receding wedge toe length data following the interruption 262 of the abstraction (i.e. $\mathrm{Q}=0.0 \mathrm{~mL} / \mathrm{s}$ ) also shows good agreement (Figure $8 \mathrm{~b}$ ), particularly 263 during the early stage of the retreat. The numerical model also depicted well the distortion of 264 the saltwater wedge as well as the transition-zone widening during the receding motion, in 265 agreement with the experimental observations (Figure 8a). 

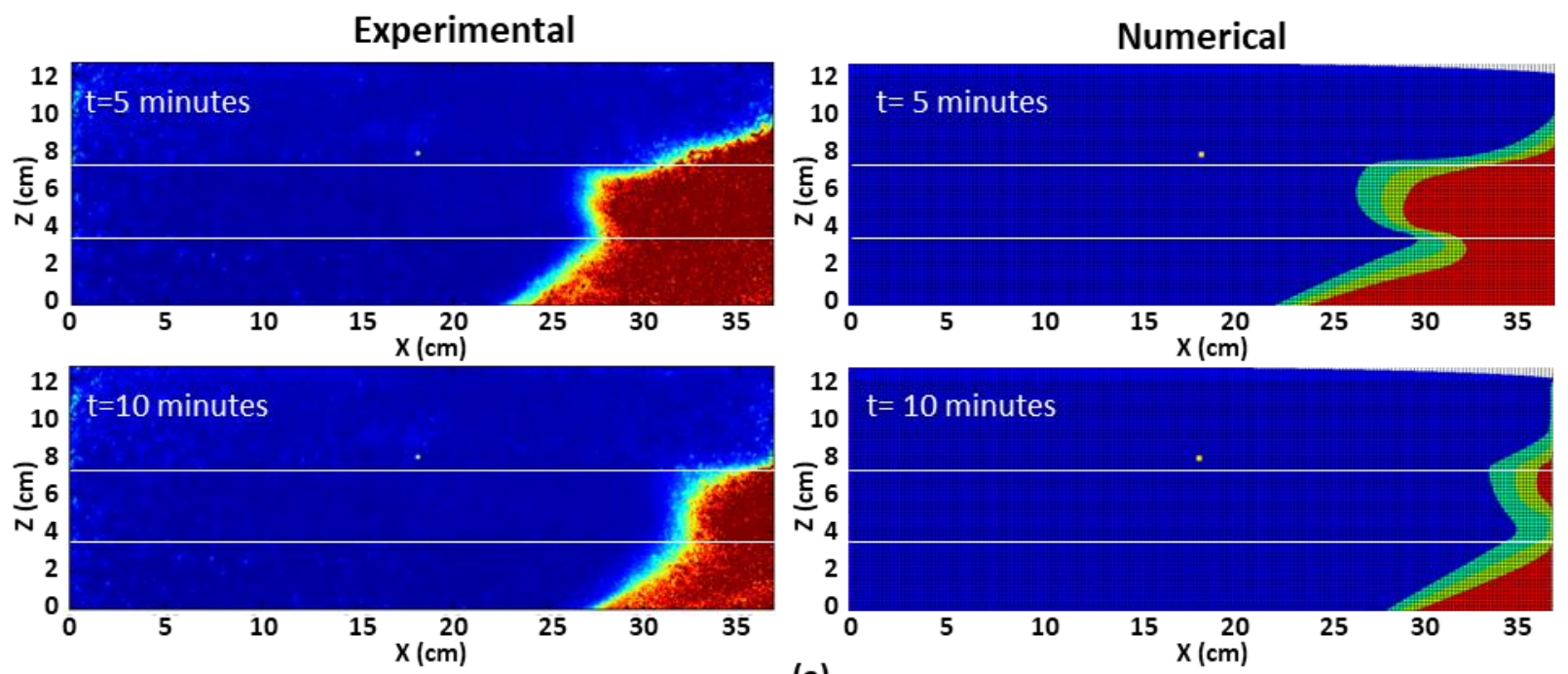

(a)

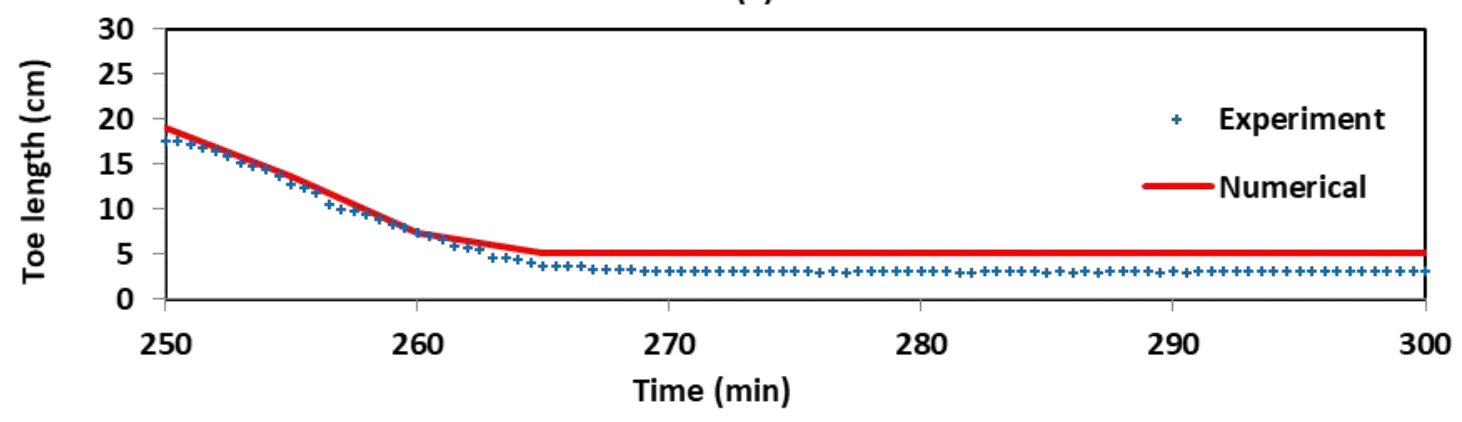

(b)

267 Figure 8 a) Comparison between experimental and numerical receding wedges following 268 pumping shut off in the heterogeneous case; b) Comparison between transient 269 experimental (blue points) and numerical (red line) toe length data in receding conditions 270 in the heterogeneous case

271 4. Sensitivity analysis

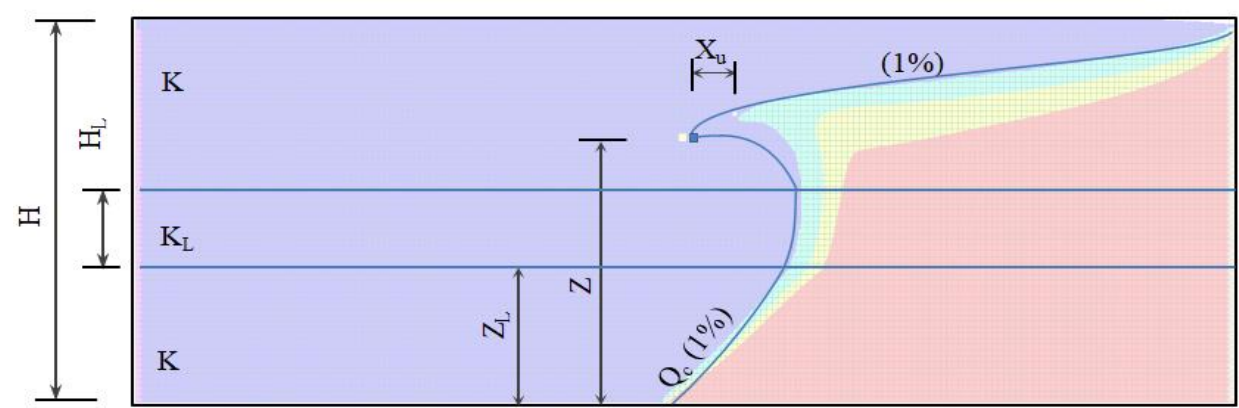

273 Figure 9 Schematic diagram of the saltwater upconing wedge in heterogeneous conditions 
275 Additional simulations were completed to explore the influence of layered heterogeneity on 276 the saltwater upconing mechanism. Specifically, the sensitivity of the critical pumping rate and

277 the critical time to the main parameters characterising heterogeneity effects was quantitatively 278 analysed. These parameters, which included the hydraulic conductivity of the middle layer $279\left(\mathrm{~K}_{\mathrm{L}}\right)$, its thickness $\left(\mathrm{H}_{\mathrm{L}}\right)$ and its position into the aquifer $\left(\mathrm{Z}_{\mathrm{L}}\right)$, were investigated for two different 280 pumping well positions. Figure 9 presents a schematic diagram of the aquifer system with the main parameters investigated herein. The critical pumping rate $\left(\mathrm{Q}_{\mathrm{c}}\right)$ was considered as the minimal abstraction rate producing steady-state upconing such that the $1 \%$ salt contour line of the cone apex crosses the bore of the well. The critical time $\left(t_{c}\right)$ was the time taken for the cone apex at $1 \%$ salt contour line to reach the well following the start of the abstraction (with $\mathrm{Q}=$ $\left.\mathrm{Q}_{\mathrm{c}}\right)$. The upconing distance $\left(\mathrm{X}_{\mathrm{U}}\right)$, was introduced to refer to the horizontal distance between the apex of upconing at $1 \%$ salt contour line and the bottom of the well.

\subsection{Effect of heterogeneity on the upconing distance with different well locations}

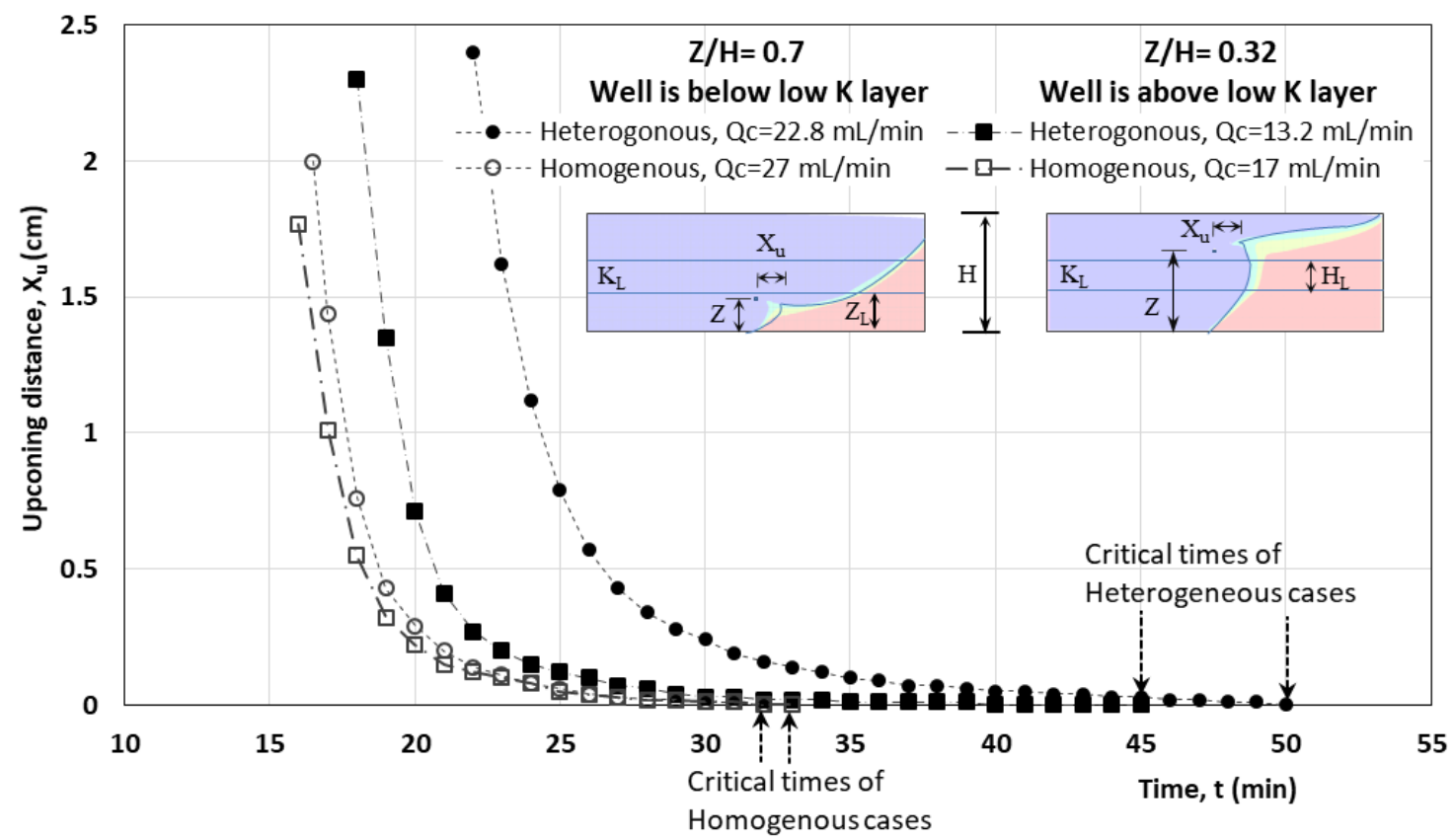

289 Figure 10 the effect of heterogeneity on the critical pumping rate and the occurrence of 290 the upconing: Heterogeneous case $\left(\mathrm{Kr}=2.36, \mathrm{H}_{\mathrm{L}} / \mathrm{H}=\mathbf{0 . 3 1}\right.$ and $\left.\mathrm{Z}_{\mathrm{L}} / \mathrm{Z}=\mathbf{0 . 5 0 5}\right)$ 


\begin{tabular}{|c|c|c|c|c|}
\hline & \multicolumn{2}{|c|}{ Shallow well $(\mathrm{Z} / \mathrm{H})=0.7$} & \multicolumn{2}{c|}{ Deep Well $(\mathrm{Z} / \mathrm{H})=0.32$} \\
\hline & Homogenous & Heterogonous & Homogenous & Heterogonous \\
\hline $\begin{array}{c}\text { Critical } \\
\text { pumping rate, } \\
\mathrm{Q}_{\mathrm{c}}(\mathrm{mL} / \mathrm{min})\end{array}$ & 27 & 22.8 & 17 & 13.2 \\
\hline
\end{tabular}

292

293 The comparison was made between homogenous and heterogeneous cases for two different

294 pumping well positions, including $\mathrm{Z} / \mathrm{H}=0.7$ (shallow well) and $\mathrm{Z} / \mathrm{H}=0.32$ (deep well). In the

295 heterogeneous case, the shallow well was located above the middle low K layer, while the deep

296 well was located below the middle layer. The purpose of this sensitivity was to study the effect

297 of heterogeneity on the critical pumping rate and to disseminate the upconing movement

298 towards the well. The critical pumping rate for each case was found by trials and errors through

299 several simulation runs using gradually increasing pumping rate.

300 Table 3 summarises the values of the critical pumping rates and Figure 10 shows the transient

301 values of the upconing distance $\mathrm{X}_{\mathrm{u}}$ in all the investigated cases, where decreasing $\mathrm{X}_{\mathrm{u}}$ values

302 characterise the movement of the saltwater towards the well. The effects of the pumping well

303 depth on the time evolution of the upconing distance $\mathrm{X}_{\mathrm{u}}$ was more pronounced in the

304 heterogeneous scenario than in the homogeneous case, where very little changes could be

305 observed. The results show that in the shallow and deep pumping scenarios, the critical

306 pumping rate was noticeably lower in the heterogeneous cases compared to the homogeneous

307 case. The presence of the low K middle layer induced a decrease of the critical pumping rate

308 of about $16 \%$ and $22 \%$, in the shallow and deep pumping scenarios, respectively. Hence, the

309 results indicate that for the similar design well parameters, the presence of a low permeability

310 layer increased the sensitivity of the well to saltwater upconing and therefore enhanced the

311 vulnerability of the coastal aquifer system to the salinisation of production wells compared to

312 the idealised homogeneous system. 


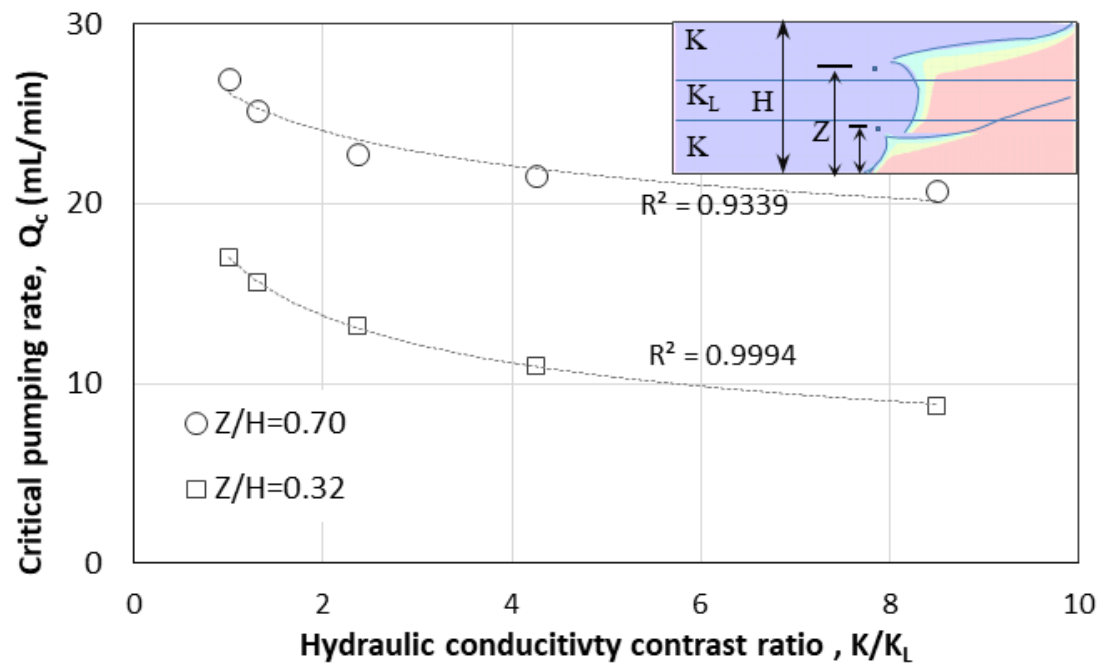

(a)

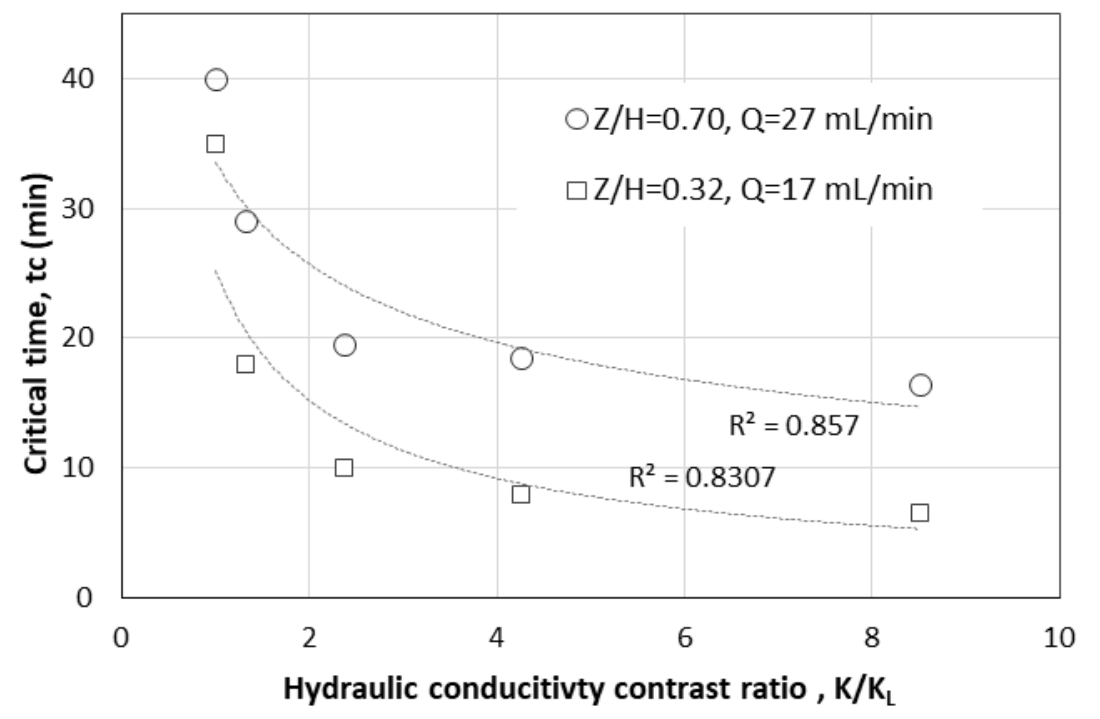

(b)

315 Figure 11 Effect of the hydraulic conductivity contrast ratio a) on the critical pumping 316 rate b) on the critical time

318 Figure 11 shows the effect of the hydraulic conductivity of the middle layer that was examined

319 for the shallow pumping well $(\mathrm{Z} / \mathrm{H}=0.7)$ and deep pumping well $(\mathrm{Z} / \mathrm{H}=0.32)$. The hydraulic

320 conductivity of the middle layer was using the dimensionless ratio $\mathrm{K} / \mathrm{K}_{\mathrm{L}}$, where $\mathrm{K}_{\mathrm{L}}$ is the

321 hydraulic conductivity of the middle layer $\mathrm{K}$ is the hydraulic conductivity of the top and bottom

322 part of the aquifer $(\mathrm{K}=85 \mathrm{~cm} / \mathrm{min})$. Five different permeability contrast ratio $\mathrm{K} / \mathrm{K}_{\mathrm{L}}$ were tested

323 from 1 to 8.5 , where $\mathrm{K} / \mathrm{K}_{\mathrm{L}}=1$ referred to the homogeneous condition. 
324 The results show that the critical pumping rate significantly decreased with increasing 325 permeability contrast (Figure $11 \mathrm{a}$ ). The results show that from $\mathrm{K} / \mathrm{K}_{\mathrm{L}}=1$ to $\mathrm{K} / \mathrm{K}_{\mathrm{L}}=8.5$, the 326 critical pumping rate decreased by $23 \%$ and $48 \%$, for $\mathrm{Z} / \mathrm{H}=0.7$ and $\mathrm{Z} / \mathrm{H}=0.32$, respectively.

327 Hence for a fixed well configuration and equivalent pumping rate increment, the saltwater 328 upconing mechanism occurred faster for decreasing hydraulic conductivity of the middle layer.

329 This may be because the freshwater flow contributing in the seaward repulsion of the saltwater 330 wedge would tend to decrease as the permeability of the middle layer decreases, thereby 331 leading to easier vertical migration of the saltwater wedge due to the abstraction, therefore a

332 faster saltwater upconing mechanism. Hence, these results also suggest that the decreasing 333 permeability of the middle layer substantially increases the vulnerability of the coastal aquifer 334 system to pumping well salinisation through saltwater upconing mechanism. The impact of the middle layer permeability is higher during water abstraction from deep well than the one of the 336 shallower well.

337 Also, the critical time was also found to noticeably decrease with increasing permeability contrast ratio $\mathrm{K} / \mathrm{K}_{\mathrm{L}}$ (Figure $11 \mathrm{~b}$ ). From the lowest to the highest $\mathrm{K} / \mathrm{K}_{\mathrm{L}}$ values tested, the critical time was decreased by $23 \mathrm{~min}$. and $28 \mathrm{~min}$, for $\mathrm{Z} / \mathrm{H}=0.7$ and $\mathrm{Z} / \mathrm{H}=0.32$, respectively. Note

340 that to determine the critical time for each $\mathrm{K} / \mathrm{K}_{\mathrm{L}}$ scenario, the values of $\mathrm{Q}_{\mathrm{c}}$ used for each well 341 position corresponded to the values found for $\mathrm{K} / \mathrm{K}_{\mathrm{L}}=1$, at which the maximum value of the 342 critical pumping rate occurred, such that to ensure the occurrence of the saltwater upconing mechanism in all cases. 


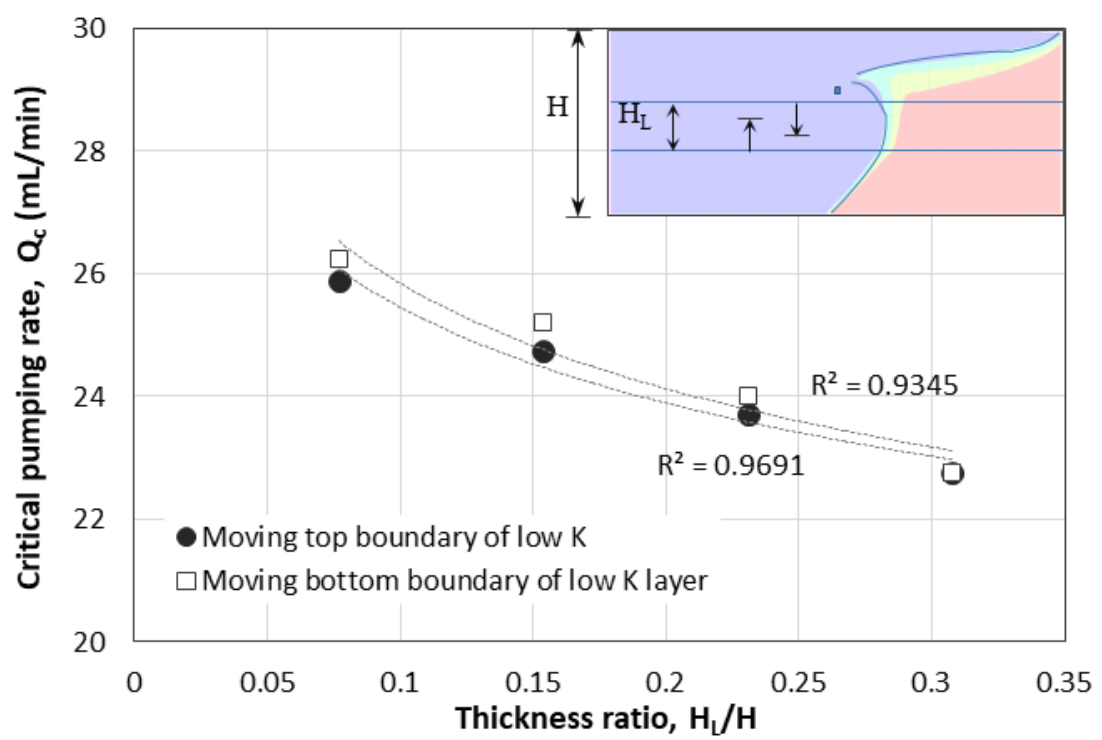

(a)

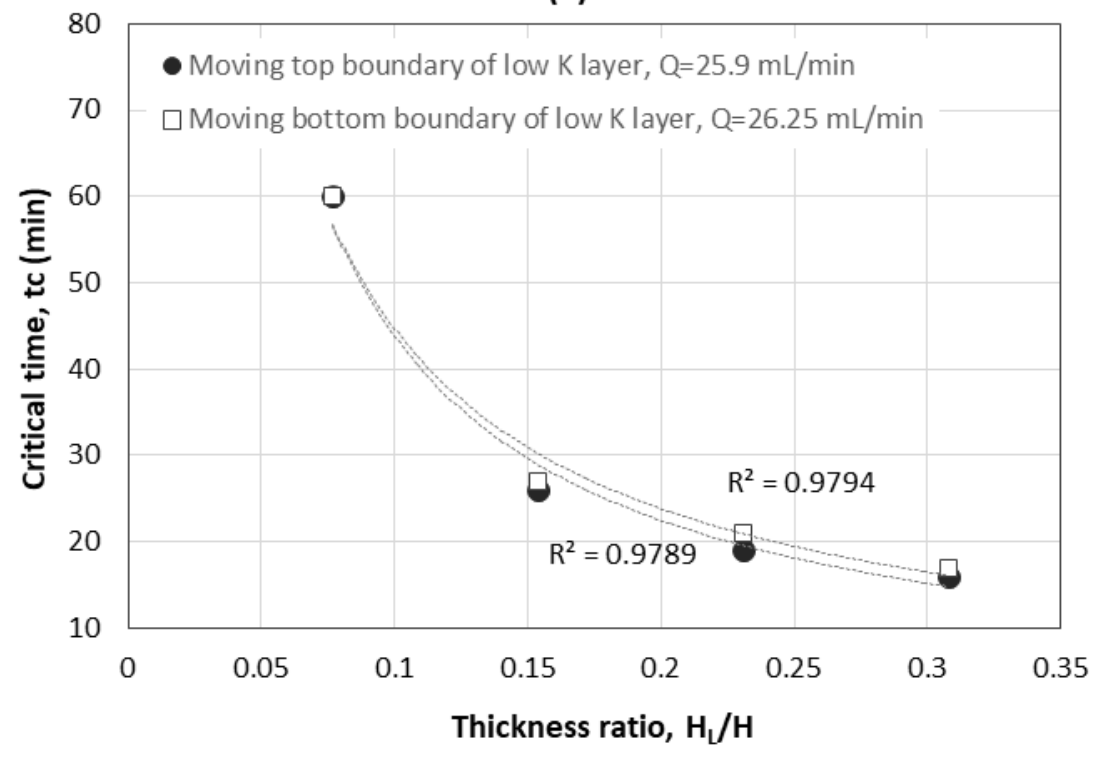

(b)

346 Figure 12 Effect of the middle layer thickness on a) the critical pumping rate and b) the critical time

348 Figure 12 shows the sensitivity of the critical pumping rate and the critical time to the thickness

349 of the low K layer. The thickness of the middle layer was examined using the thickness ratio

$350\left(\mathrm{H}_{\mathrm{L}} / \mathrm{H}\right)$, where $\mathrm{H}_{\mathrm{L}}$ is the thickness of the middle layer and $\mathrm{H}$ is the aquifer thickness $(\mathrm{H}=13$

$351 \mathrm{~cm})$. Two scenarios were tested: in the first, the top boundary of the low $\mathrm{K}$ middle layer was moved downwards; in the second scenario, the bottom layer was moved upwards. 
353 Figure 12a shows that increasing thickness of the low K layer lowers the critical pumping rate,

354 regardless of where the layer boundary change occurs. Therefore for equivalent pumping rate

355 increment, larger the low permeability middle layer induced the earlier occurrence of saltwater

356 upconing mechanism. From $\mathrm{H}_{\mathrm{L}} / \mathrm{H}=0.077$ to $\mathrm{H}_{\mathrm{L}} / \mathrm{H}=0.31$, the critical pumping rate decreased

357 by $14 \%$ in the case where the top boundary was changed, while it decreased by $15 \%$ when the

358 bottom boundary was changed. These data show that the sensitivity of the critical pumping rate

359 to the thickness ratio variations was nearly the same, whether the top boundary or the bottom

360 boundary was changed.

361 The effect of thickness ratio on the critical time (Figure 12b) was investigated using the highest

362 value of critical pumping rate for each respective scenario for all remaining thickness ratio.

363 The data show that for a fixed pumping rate, the critical time considerably decreased as the

364 thickness ratio $\mathrm{H}_{\mathrm{L}} / \mathrm{H}$ was increased. From the lowest to the highest $\mathrm{H}_{\mathrm{L}} / \mathrm{H}$ values tested, the

365 critical time was decreased by almost $40 \mathrm{~min}$ in both the top and bottom boundary change

366 scenarios, which clearly show that the increased thickness of the middle low K layer facilitated

367 to saltwater upconing process, thereby inducing faster salinisation of the pumping well. 


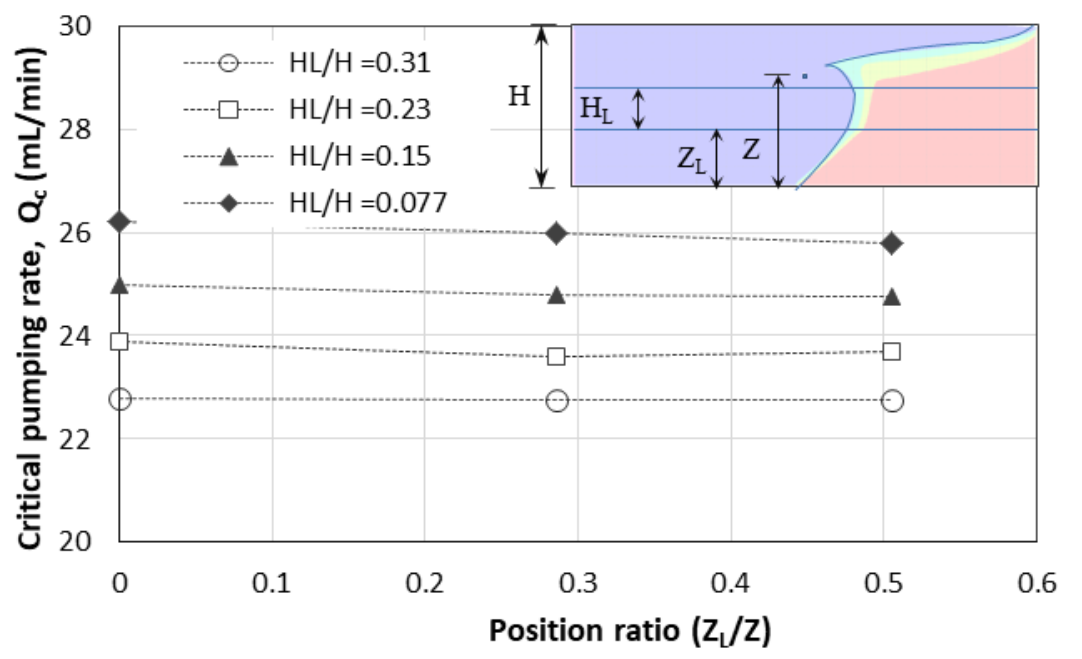

(a)

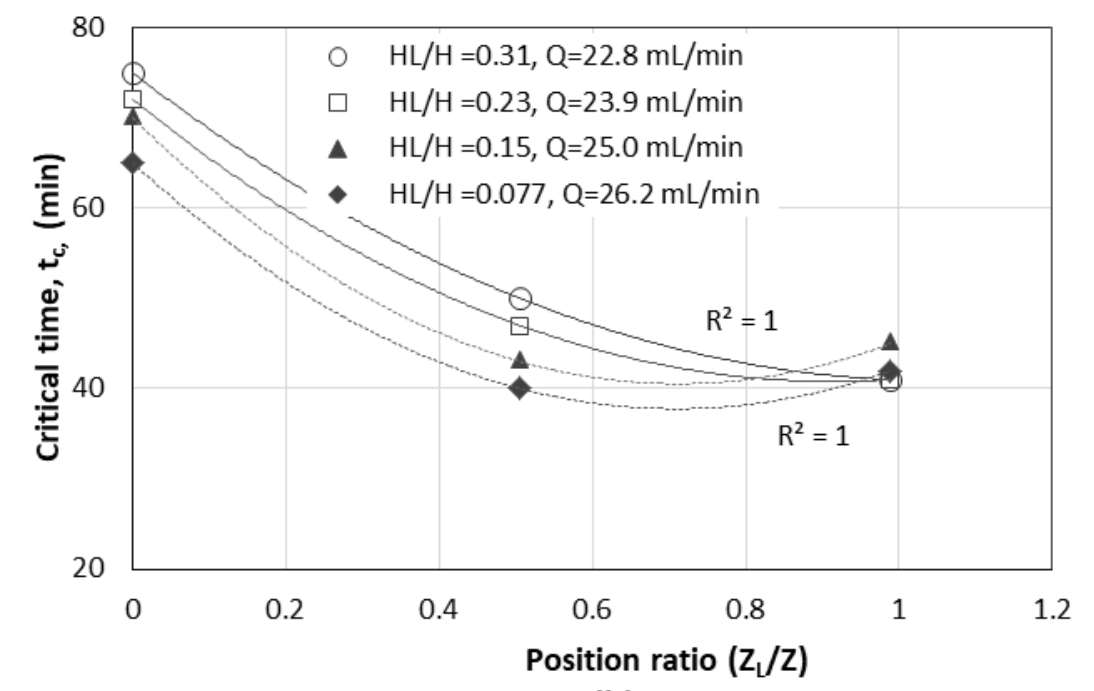

(b)

374 Figure 13 Effect of the low $K$ layer position on a) the critical pumping rate and b) the 375 critical time

376 Figure 13 shows the sensitivity of the saltwater upconing mechanism to the position of the low

$377 \mathrm{~K}$ layer. The position ratio $\left(\mathrm{Z}_{\mathrm{L}} / \mathrm{Z}\right)$ was considered to examine the effect of the varying the 378 position of the middle layer, where $\mathrm{Z}_{\mathrm{L}}$ is the distance between the bottom boundary of the 379 middle layer and $\mathrm{Z}$ is the pumping well depth, the distance between the well and the aquifer 380 bottom. Four different values of thickness ratio $\mathrm{H}_{\mathrm{L}} / \mathrm{H}$ were tested for the sake of completeness.

381 The results show that varying the depth of low K layer caused negligible effects on the critical 382 pumping rate (Figure 13a), but induced noticeable changes on the critical time (Figure 13b), 
383 which was found to decreases when the ratio $Z_{L} / Z$ was increased, the critical time decreases.

384 This means that as the low K layer was moved closer to the well, the saltwater upconing

385 mechanism occurred faster, although this could not be observed for values of $Z_{\mathrm{L}} / \mathrm{Z}$ exceeding 3860.4 where the critical time slightly increased again particularly for $\mathrm{H}_{\mathrm{L}} / \mathrm{H}=0.23$ and $\mathrm{H}_{\mathrm{L}} / \mathrm{H}=$ $387 \quad 0.31$.

\section{$388 \quad$ 5. Summary and conclusions}

389 This investigation presented for the first time a quantitative analysis of the influence of layered 390 heterogeneity on the saltwater upconing mechanism laboratory-scale unconfined coastal 391 aquifer model. Physical experiments were first completed to observe the upconing process 392 using automated image analysis. To quantify the effect of heterogeneity on the upconing 393 process, the experimental results were compared to the data of the homogeneous case of 394 Abdoulhalik \& Ahmed (2018), that has similar hydrostatic conditions, and the same abstraction rates were used. The numerical model SEAWAT was used for validation, and the resulting model of the heterogeneouse scenario was used to perform additional simulations to explore

397 the sensitivity of the critical pumping rate and the critical time to the main parameters 398 characterising the middle layer, which included its permeability, its thickness and its position 399 into the unconfined aquifer.

400 The experimental results showed that the presence of layered heterogeneity noticeably affected 401 the shape and the intrusion length of the upconing wedge. The final shape of the upconing 402 wedge in the heterogeneous case exhibited a wider transition-zone and a rather bulged shape, as opposed to the curved shape and the thin transition zone observed in the homogeneous case.

404 Laboratory observations nonetheless showed that the saltwater upconing mechanism was 405 "triggered" for the same abstraction rate as in the homogeneous case, for the pumping rate 406 increment considered. 
The numerical results of the heterogeneous unconfined aquifer model provided matched very

408

409

410

411

412

413

414

415

416

417 well with the experimental data for both the transient toe length data and the shape of the steady-state saltwater wedges for different pumping rates. The sensitivity analysis performed using the resulting numerical model revealed that the critical pumping rate and the critical time was found to decrease considerably with decreasing hydraulic conductivity and thickness of the middle layer, which evidences the higher vulnerability to the saltwater upconing of coastal aquifer systems exhibiting layers of low permeability compared to an idealised homogeneous system. The results also showed that varying the position the interlayer induced very little change on the critical pumping rate, but the critical time would tend to decrease as the low permeability layer was moved deeper away from the pumping well, particularly for small values of middle layer thickness.

\section{Acknowledgements}

The experiments of this work were carried out at Queen's University Belfast when the first and third authors were associated with the institution.

\section{References}

Abdelgawad, A. M., Abdoulhalik, A., Ahmed, A. A., Moutari, S., \& Hamill, G. (2018). Transient Investigation of the Critical Abstraction Rates in Coastal Aquifers: Numerical and Experimental Study. Water Resources Management, 32(11), 3563-3577. https://doi.org/10.1007/s11269-018-1988-3.

Abdoulhalik, A., \& Ahmed, A. A. (2017). How does layered heterogeneity affect the ability of subsurface dams to clean up coastal aquifers contaminated with seawater intrusion? Journal of Hydrology, 553(September), 708-721. https://doi.org/10.1016/j.jhydrol.2017.08.044.

Abdoulhalik, A., \& Ahmed, A. A. (2018). Transient investigation of saltwater upconing in laboratory-scale coastal aquifer. Estuarine, Coastal and Shelf Science, 214(June), 149160. https://doi.org/10.1016/j.ecss.2018.09.024.

Dose, E. J., Stoeckl, L., Houben, G. J., Vacher, H. L., Vassolo, S., Dietrich, J., \& Himmelsbach, T. (2014). Experiments and modeling of freshwater lenses in layered aquifers: Steady state interface geometry. Journal of Hydrology. https://doi.org/10.1016/j.jhydrol.2013.10.010

Ferguson, G., \& Gleeson, T. (2012). Vulnerability of coastal aquifers to groundwater use and 
climate change. Nature Climate Change, 2(5), 342-345.

https://doi.org/10.1038/nclimate1413.

Guo, W., \& Langevin, C. D. (2002). User's Guide to SEAWAT: A computer program for simulation of three-dimensional variable-density ground-water flow. USGS Techniques of Water Resources Investigations.

Houben, G., \& Post, V. E. A. (2017). The first field-based descriptions of pumping-induced saltwater intrusion and upconing. Hydrogeology Journal, 25(1), 243-247. https://doi.org/10.1007/s10040-016-1476-x.

Johannsen, K., Kinzelbach, W., Oswald, S., \& Wittum, G. (2002). The saltpool benchmark problem - Numerical simulation of saltwater upconing in a porous medium. Advances in Water Resources, 25(3), 335-348. https://doi.org/10.1016/S0309-1708(01)00059-8

Ketabchi, H., Mahmoodzadeh, D., Ataie-Ashtiani, B., Werner, A. D., \& Simmons, C. T. (2014). Sea-level rise impact on fresh groundwater lenses in two-layer small islands. Hydrological Processes, 28(24), 5938-5953. https://doi.org/10.1002/hyp.10059.

Liu, Y., Mao, X., Chen, J., \& Barry, D. A. (2014). Influence of a coarse interlayer on seawater intrusion and contaminant migration in coastal aquifers. Hydrological Processes. https://doi.org/10.1002/hyp.10002.

Lu, C., Chen, Y., Zhang, C., \& Luo, J. (2013). Steady-state freshwater-seawater mixing zone in stratified coastal aquifers. Journal of Hydrology, 505, 24-34. https://doi.org/10.1016/j.jhydrol.2013.09.017.

Mehdizadeh, S. S., Werner, A. D., Vafaie, F., \& Badaruddin, S. (2014). Vertical leakage in sharp-interface seawater intrusion models of layered coastal aquifers. Journal of Hydrology, 519(PA), 1097-1107. https://doi.org/10.1016/j.jhydrol.2014.08.027

Mehdizadeh, S. S., Vafaie, F., \& Abolghasemi, H. (2015). Assessment of sharp-interface approach for saltwater intrusion prediction in an unconfined coastal aquifer exposed to pumping. Environmental Earth Sciences, 73(12), 8345-8355. https://doi.org/10.1007/s12665-014-3996-9.

Mehdizadeh, S. S., Karamalipour, S. E., \& Asoodeh, R. (2017). Sea level rise effect on seawater intrusion into layered coastal aquifers (simulation using dispersive and sharpinterface approaches). Ocean \& coastal management, 138, 11-18.

Michael, H. A., Post, V. E., Wilson, A. M., \& Werner, A. D. (2017). Science, society, and the coastal groundwater squeeze. Water Resources Research, 53(4), 2610-2617.

Noorabadi, S., Nazemi, A. H., Sadraddini, A. A., \& Delirhasannia, R. (2017). Laboratory investigation of water extraction effects on saltwater wedge displacement. Global Journal of Environmental Science and Management-Gjesm, 3(1), 21-32. https://doi.org/10.22034/gjesm.2017.03.01.003.

Reilly, T. E., \& Goodman, A. S. (1987). Analysis of saltwater upconing beneath a pumping well. Journal of Hydrology, 89(3-4), 169-204. https://doi.org/10.1016/00221694(87)90179-X 
Simmons, C. T., Fenstemaker, T. R., \& Sharp, J. M. (2001). Variable-density groundwater flow and solute transport in heterogeneous porous media: Approaches, resolutions and future challenges. Journal of Contaminant Hydrology. https://doi.org/10.1016/S01697722(01)00160-7.

Stoeckl, L., \& Houben, G. (2012). Flow dynamics and age stratification of freshwater lenses: Experiments and modeling. Journal of Hydrology, 458, 9-15. https://doi.org/10.1016/j.jhydrol.2012.05.070.

Strack, O. D. L., \& Ausk, B. K. (2015). A formulation for vertically integrated groundwater flow in a stratified coastal aquifer. Water Resources Research, 51(8), 6756-6775.

Voss, C. I., \& Souza, W. R. (1987). Variable density flow and solute transport simulation of regional aquifers containing a narrow freshwater-saltwater transition zone. Water Resources Research, 23(10), 1851-1866. https://doi.org/10.1029/WR023i010p01851

Werner, A. D., Jakovovic, D., \& Simmons, C. T. (2009). Experimental observations of saltwater up-coning. Journal of Hydrology, 373(1-2), 230-241. https://doi.org/10.1016/j.jhydrol.2009.05.004.

Wirojanagud, P., \& Charbeneau, R. J. (1985). Saltwater upconing in unconfined aquifers. Journal of Hydraulic Engineering, 111(3), 417-434. https://doi.org/10.1061/(ASCE)0733-9429(1985)111:3(417).

Zhou, Q., Bear, J., \& Bensabat, J. (2005). Saltwater upconing and decay beneath a well pumping above an interface zone. Transport in Porous Media, 61(3), 337-363. https://doi.org/10.1007/s11242-005-0261-4. 